\title{
FICOFLÓRULA DO LAGO AMAPÁ EM RIO BRANCO- ACRE, II: CHLOROPHYTA
}

\author{
KEPPELER, E. C., ${ }^{1}$ LOPES, M. R. M. ${ }^{2}$ e LIMA, C. S. ${ }^{3}$ \\ ${ }^{1}$ Mestrado em Ecologia e Manejo de Recursos Naturais/Laboratório de Limnologia, Universidade Federal do Acre - \\ UFAC, Rodovia BR 364 Km 04, CEP 69915-900, Rio Branco, AC, Brasil \\ ${ }^{2}$ Departamento de Ciências da Natureza - UFAC \\ ${ }^{3}$ Laboratório de Limnologia - UFAC \\ Correspondência para: Erlei Cassiano Keppeler, Laboratório de Limnologia, Universidade Federal do Acre, Rua 1B \\ esquina 2A, nº 12, Parque das Nações, CEP 69907-270, Rio Branco, AC, Brasil, e-mail: erlei@ hotmail.com \\ Recebido em 19/03/98 - Aceito em 17/11/98 - Distribuído em 22/12/99 \\ (Com 14 figuras)
}

\begin{abstract}
Algal Flora of Lake Amapá in Rio Branco, Acre State, II: Chlorophyta

In this study, 15 samples were collected on a bi-monthly basis, during the period between March and May 1994, and 3 additional samples were collected, one in each of the months of July, October and November 1994. All the samples were collected in Lake Amapá (lat. 10²'36”'S, long. 6750'24'W), which is located in Rio Branco, Acre State, Brazil. Ten táxons, of Chlorophyta were registered: Botryococcaceae (2), Treubariaceae (1), Volvocaceae (2), Closteriaceae (3) e Desmidiaceae (2). All taxa identified are first citations for Acre State.

Key words: plankton, taxonomy of Chlorophyta, Acre State.

\section{RESUMO}

Este trabalho está baseado em 15 amostras coletadas quinzenalmente, entre março e maio de 1994, adicionadas de três coletas mensais em julho, outubro e novembro de 1994, no Lago Amapá (lat. 10²'36"S, long. 6750'24”W) em Rio Branco, Estado do Acre. Registrou-se da divisão Chlorophyta 10 táxons, sendo Botryococcaceae (02), Treubariaceae (01), Volvocaceae (02), Closteriaceae (03) e Desmidiaceae (02). Todos os táxons identificados são citados pela primeira vez para o Estado do Acre.
\end{abstract}

Palavras-chave: fitoplâncton, taxonomia de Chlorophyta, Estado do Acre.

\section{INTRODUÇÃO}

Este trabalho faz parte da Ficoflórula do Lago Amapá, Rio Branco, Estado do Acre. Refere-se à Divisão Chlorophyta e o anterior restringiu-se à Classe Euglenophyceae (Keppeler et al., 1999).

\section{MATERIAL E MÉTODOS}

A metodologia utilizada foi a mesma descrita em Keppeler et al. (1998). As identificações foram baseadas em algumas chaves de Bourrely
(1972); Nogueira (1991) e Marques-Lopes (1992), dentre outras.

\section{RESULTADOS}

Chlorophyta

Chlorophyceae

Chlorococcales

Botryococcaceae

- Dictyosphaerium ehrenbergianum Nägeli Indivíduo colonial, células oblongas, ovóides ou reniformes, unidas por filamentos mucilaginosos, 5-8 × 3-7 $\mu \mathrm{m}$, cloroplasto parietal, um pirenóide (Fig. 10). 


\title{
Chave para identificação dos táxons encontrados
}

\author{
1 - Indivíduo solitário \\ 2 - Célula dividida em duas semicélulas \\ 3 - Célula com constrição mediana \\ 4 - Célula com processos \\ Staurastrum volans var. fuquenense \\ 4 - Célula sem processos \\ Staurastrum hirsutum \\ 3 - Célula sem constrição mediana \\ 5 - Células com processos apicais setáceos.. \\ 5 - Células sem processos apicais setáceos \\ 6 - Ápices arredondados. \\ 6 - Ápices agudos \\ Closterium küetzingii var. küetzingii \\ Closterium aciculare var. aciculare \\ Closterium gracile \\ 2 - Célula não dividida em duas semicélulas, apresentando quatro apêndices. \\ Pachycladella umbrina \\ 1 - Indivíduo colonial \\ 7 - Células flageladas \\ 8 - Cloroplasto com um pirenóide \\ Eudorina unicocca \\ 8 - Cloroplasto com dois ou mais pirenóides \\ 7 - Células não-flageladas \\ 9 - Células esféricas ligadas por fios de mucilagem \\ Dictyosphaerium pulchellum var. pulchellum \\ 9 - Células oblongas, ovóides ou reniformes ligadas por fios de mucilagem \\ Dictyosphaerium ehrenbergianum
}

- Dictyosphaerium pulchellum Wood var. pulchellum

Indivíduo colonial, células esféricas, unidas por filamentos mucilaginosos, 4-6 $\mu \mathrm{m}$ diâm., cloroplasto único, parietal, um pirenóide (Fig. 11).

Treubariaceae

- Pachycladella umbrina (G. M. Smith) Silva Indivíduo solitário, célula esférica, 8-10 $\mu \mathrm{m}$ diâm., com quatro apêndices vermelhos a marrons, longos, 43-48 $\mu \mathrm{m}$ comp., gradualmente afilados, 2-denticulados, parede celular hialina, delicada; cloroplasto único, parietal, um pirenóide (Fig. 13).

Volvocales

Volvocaceae

\section{- Eudorina unicocca G. M. Smith}

Indivíduo colonial, livre-natante, colônia mais ou menos globosa, 95-111 × 80-91 $\mu \mathrm{m}$, mucilagem evidente, 32 celulados, célula com pólo posterior mamiliforme, $12 \times 11 \mu \mathrm{m}$, cromoplastídio poculiforme, um pirenóide, estigma anterior, dois flagelos de comprimentos iguais (Fig. 12).

- Eudorina elegans Ehrenberg var. elegans Indivíduo colonial, livre-natante, colônia mais ou menos globosa, 89-100 × 80-92 $\mu \mathrm{m}$, mucilagem evidente, 16-32 celulados, cromoplastídio poculiforme; 2 ou mais pirenóides, 2 flagelos de comprimentos iguais (Fig. 14).

\section{Zygenemaphyceae \\ Desmidiales \\ Closteriaceae}

- Closterium aciculare T. West. var. aciculare Indivíduo solitário, célula estreita e alongada, 210$450 \times 6-12 \mu \mathrm{m}$, quase reta, curvando-se para a região apical, ápices acuminado-arredondados, parede celular lisa e incolor (Fig. 3).

- Closterium gracile De Brébisson

Indivíduo solitário, célula reta, estreita e alongada, 120-220 × 4,5-6 $\mu \mathrm{m}$, ápices arredondados, curvados, cloroplastídio axial, 5-7 pirenóides por semi-célula, parede celular lisa e incolor (Figs. 4 e 5).

- Closterium küetzingii De Brébisson var. küetzingii

Indivíduo solitário, célula praticamente reta, região mediana fusiforme, processos apicais setáceos, ápices arredondados, levemente curvados, 230-450 × 10-15 $\mu \mathrm{m}$, parede celular estriada, estrias 8 em $10 \mu \mathrm{m}$, espessamento apical, cloroplasto axial, 5-6 pirenóides por semicélula (Figs. 1 e 2). 


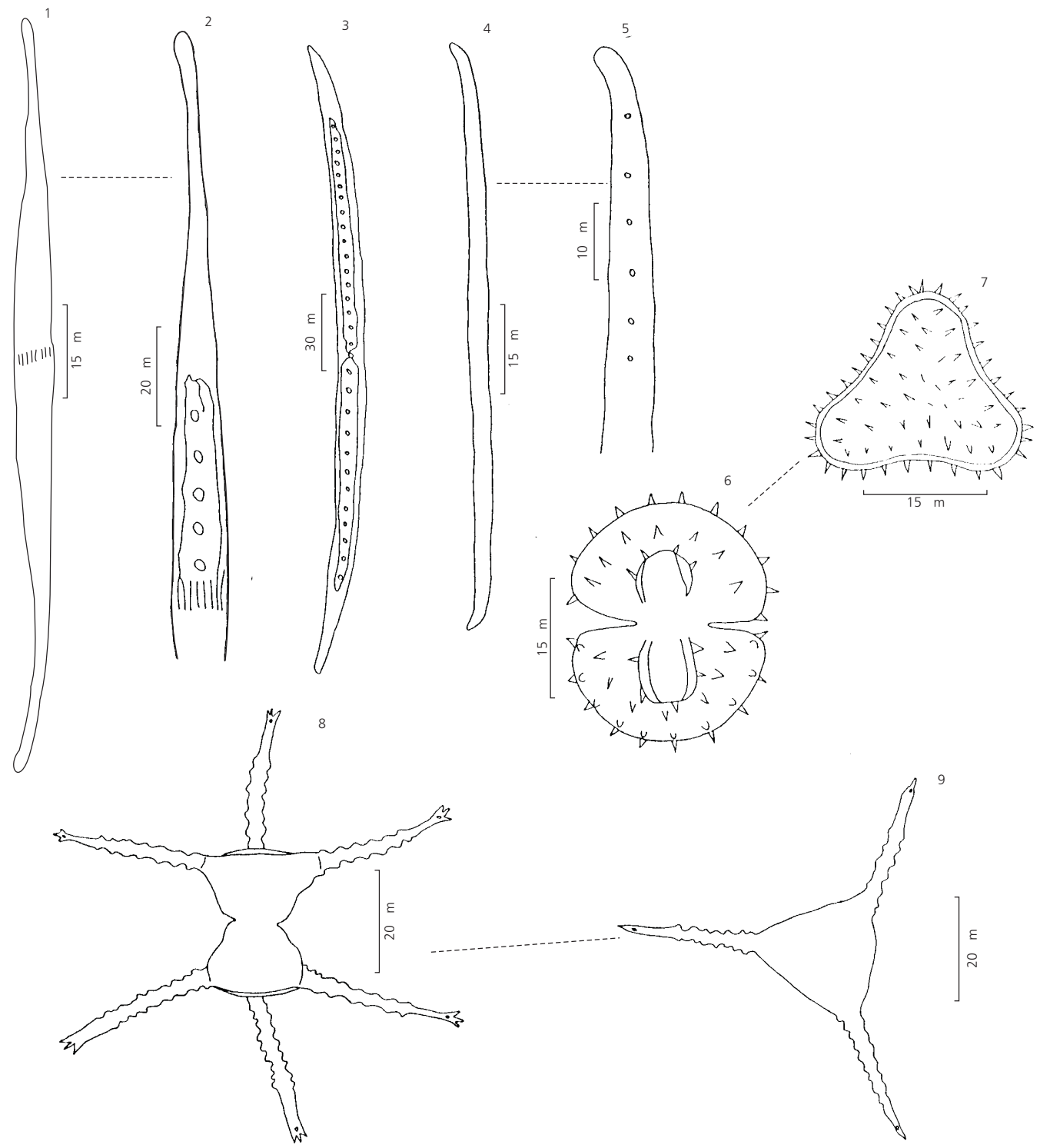

Figs. 1 e $2-$ Closterium küetzingii Brébisson var. küetzingii. Fig. 3 - Closterium aciculare T. West var. aciculare. Figs. 4 e 5 - Closterium gracile Brébisson. Figs. 6 e 7 - Staurastrum hirsutum (Ehrenberg) Ralfs, 6 - vista frontal, 7 - vista apical. Figs. 8 e 9 - Staurastrum volans West \& West var. fuquenense Coesel, 8 - vista frontal, 9 - vista apical. 

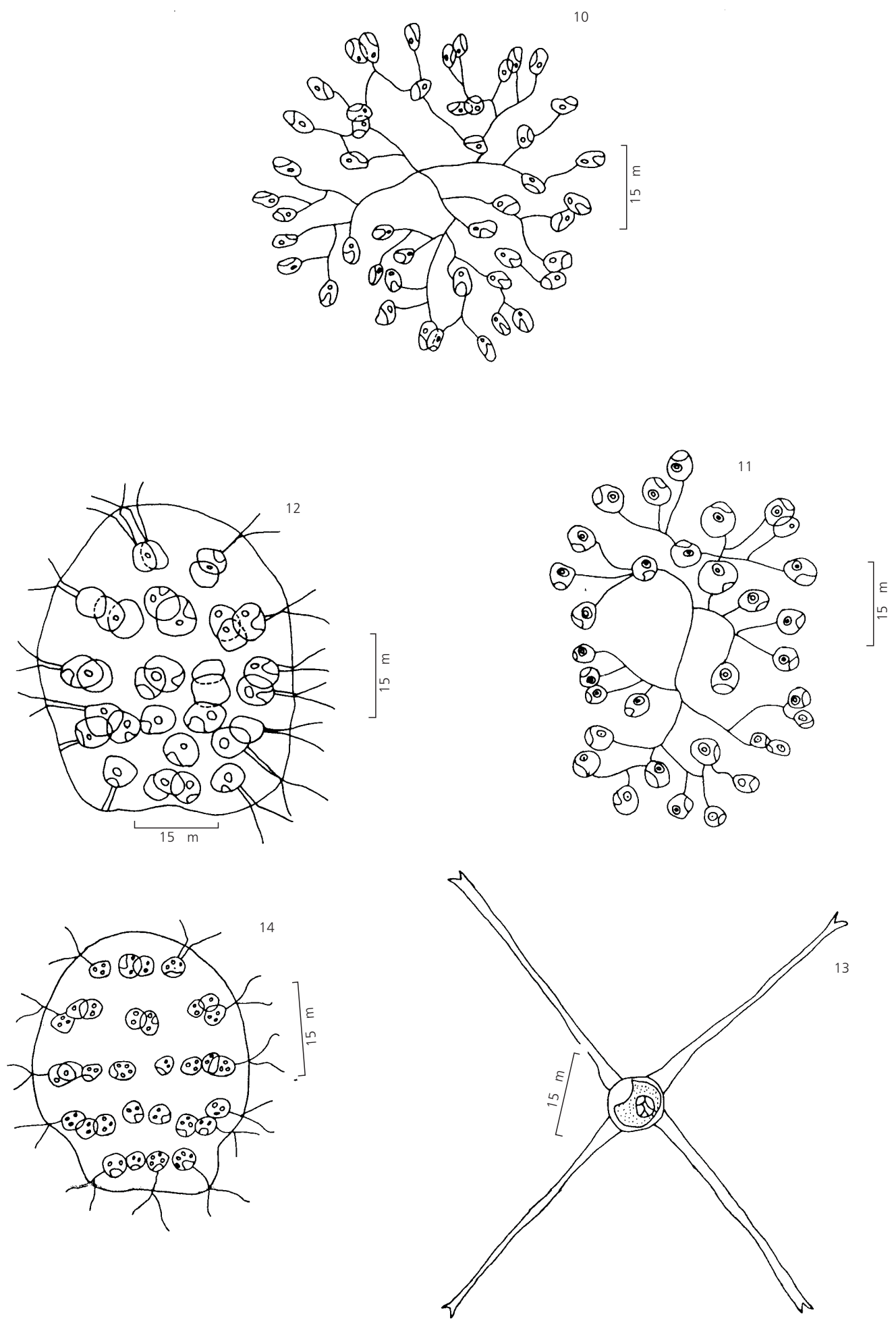

Fig. 10 - Dictyosphaerium ehrenbergianum Nägeli, Fig. 11 - Dictyosphaerium pulchellum Wood var. pulchellum. Fig. 12 - Eudorina unicocca G. M. Smith. Fig. 13 - Pachycladella umbrina (G. M. Smith) Silva. Fig. 14 - Eudorina elegans Ehrenberg var. elegans. 
Desmidiaceae

- Staurastrum hirsutum (Ehrenberg) Ralfs Indivíduo solitário, semi-célula semiorbicular ou hemisférica, constrição mediana profunda, 38-54 $\times 30,5-54 \mu \mathrm{m}$, istmo $11 \mathrm{~mm}$ larg., parede celular com espinhos (Figs. 6 e 7).

- Staurastrum volans West \& West var. fuquenense Coesel

Indivíduo solitário, semicélula ciatiforme a suborbicular, constrição mediana profunda, 26-29 × 15$18 \mu \mathrm{m}$ sem processos, istmo $8 \mathrm{~mm}$ larg., 2-3 processos longos, delgados, margens crenuladas, ápices denticulados, 29-42 $\mu \mathrm{m}$ comp., parede celular lisa (Figs. 8 e 9).

\section{CONCLUSÕES}

O estudo das Chlorophyta encontradas no Lago Amapá permitiu-nos algumas conclusões:

a) $\mathrm{Na}$ totalidade desta divisão foi registrado 10 táxons.

b) A família melhor representada foi a Zygnemaphyceae, como também o gênero Closterium.

c) Todos os táxons constituem primeira citação para o Estado do Acre. d) Sugerimos a análise do material in vivo e dentro do contexto populacional, visto que o uso de soluções preservativas e fixadoras podem provocar a perda de flagelos, deformações celulares e dissoluções de colônias.

\section{REFERÊNCIAS BIBLIOGRÁFICAS}

BOURRELLY, P., 1972, Les algues d'eau douce: Initiation à la systematique, 1: les algues vertes. Paris, N. Boubée, v. $1,572 \mathrm{p}$.

KEPPELER, E. C., MARQUES-LOPES, M. R. \& LIMA, C. de S., 1999, Ficoflórula do Lago Amapá em Rio BrancoAcre, I: Euglenophyceae. Revista Brasileira de Biologia, 59(4): 679-686.

MARQUES-LOPES, M. R., 1992, Desmidioflórula do Lago Novo Andirá (Rio Acre), Estado do Amazonas, Brasil. Dissertação de Mestrado, Universidade de São Paulo, São Paulo, 182p.

NOGUEIRA, I. S., 1991, Chlorococcales sensu lato (Chlorophyceae) do Municipio do Rio de Janeiro e Arredores, Brasil. Inventário e Considerações Taxonômicas. Dissertação de Mestrado, Universidade Federal do Rio de Janeiro, Rio de Janeiro, 355p. 